\title{
ANALISIS PERBANDINGAN CITRA MEREK PRODUK KOSMETIK WARDAH DENGAN KOSMETIK LA TULIPE DI KOTA BIMA
}

\section{COMPARATIVE ANALYSIS OF WARDAH COSMETIC PRODUCT BRAND IMAGE WITH COSMETICS LA TULIPE IN BIMA CITY}

\author{
Suryani ${ }^{1}$, Ismunandar ${ }^{2}$ \\ ${ }^{12}$ Manajemen, Sekolah Tinggi Ilmu Ekonomi (STIE) Bima \\ ssuryani17.stiebima@gmail.com \\ 2andar.stiebima@gmail.com
}

\begin{abstract}
ABSTRAK
Kosmetik memang tidak jauh dari wanita, dan kebanyakan memang membutuhkan riasan seperti alas bedak, bedak, lipstick, blus on, eye liner, maskara dan sebagainya. Saat ini dampak perkembangan kosmetik sangat menjamur oleh karena itu para industri kosmetik harus mampu mempertahankan citra yang baik di mata masyarakat. Tujuan dari penelitian ini yaitu untuk mengetahui perbedaan citra merek antara produk kosmetik Wardah dengan kosmetik La Tulipe di Kota Bima. Didalam penelitian ini metode yang digunakan yaitu penelitian komperatif merupakan penelitian yang sifatnya menguraikan tentang keadaan objek penelitian, khususnya pada citra merek produk kosmetik Wardah dan La tulipe. Sampel yang digunakan yaitu 50 responden pengguna kosmetik wardah dan 50 responden pengguna kosmetik La Tulipe. Instrumen yang diperlukan dalam penelitian ini adalah kuesioner atau angket yang akan diukur memakai skala likert bobotnya 1 sampai 5 . Teknik pengumpulan sampel didalam penelitian ini dikerjakan dengan teknik purposive sampling. Teknik pengumpulan data yang digunakan antara lain observasi, wawancara, kuesioner, dan studi pustaka dengan menggunakan jenis data kuantitatif dan data primer. Teknik analisis data yang digunakan yaitu uji validitas, uji reliabilitas, dan uji beda independent samples test. Hasil peneletian nya adalah nilai probabilitas atau sig.(2-tailed) 0,011 < 0,05 , maka $\mathrm{H}_{0}$ ditolak dan $\mathrm{H}_{\mathrm{a}}$ diterima yang berarti bahwa ditemukan perbedaan yang signifikan Citra Merek Antara Produk kosmetik Wardah dan Produk kosmetik La Tulipe di Kota Bima.
\end{abstract}

Keywords: Citra Merek, Wardah, La Tulipe

\begin{abstract}
Cosmetics are indeed not far from women, and most of them really need make-up such as foundation, powder, lipstick, blouse, eye liner, mascara and so on. Currently the impact of the development of cosmetics is mushrooming, therefore the cosmetics industry must be able to maintain a good image in the eyes of the public. The purpose of this study was to determine the difference in brand image between Wardah cosmetic products and La Tulipe cosmetics in Bima City. In this study, the method used is comparative research which describes the state of the research object, especially the brand image of Wardah and La Tulipe cosmetic products. The sample used is 50 respondents who use cosmetics wardah and 50 respondents who use cosmetics La Tulipe. The instrument needed in this study is a questionnaire or questionnaire which will be measured using a Likert scale weighing 1 to 5. The sample collection technique in this study is done by using purposive sampling technique. Data collection techniques used include observation, interviews, questionnaires, and literature study using quantitative data types and primary data. The data analysis techniques used were validity test, reliability test, and independent samples test. The research result is a probability value or sig. (2tailed) $0.011<0.05$, then $\mathrm{HO}$ is rejected and Ha is accepted, which means that a significant difference was found in the brand image between Wardah cosmetic products and La Tulipe cosmetic products in Bima City.
\end{abstract}

Keywords: Brand Image, Wardah, La Tulipe 


\section{PENDAHULUAN}

Sebagai Negara yang berkembang, Indonesia merupakan pasar yang potensial. Kejadian tersebut memaparkan semakin ketat persaingan dilingkungan bisnis. Dalam menghadapi persaingan yang semakin ketat, perusahaan harus mampu menciptakan keunikannya tersendiri dan membentuk citra merek yang positif untuk produk yang dikeluarkannya agar dapat menonjol dari pesaing tersebut. Mengingat perekonomian dan gaya hidup masyarakat Indonesia saat ini makin pintar dan sering mencari hal-hal baru, maka para pemasar harus jeli untuk menarik perhatian konsumen, menjaga pangsa pasar dan mengembangkannya agar dapat menempati pangsa pasar, Citra merek sangat penting bagi suatu industri kosmetik, karena citra merek yang bermutu mampu menciptakan kualitas yang positif bagi pelanggan saat membeli atau menggunakan merek terentu. Begitu pula sebaliknya, jika citra merek dimata pelanggan buruk, kemungkinan besar pelanggan tidak akan membeli produk tersebut, (Erni Yunaida, 2017).

Brand image merupakan seperangkat ingatan di benak pelanggan mengenai sebuah Brand, baik itu positif ataupun negative. Brand image yang positif memberikan manfaat bagi produser lebih dikenal pelanggan, dengan kata lain pelanggan akan menentukan pilihan mereka untuk membeli produk yang memiliki merek yang baik. Sebaliknya, apabila brand image negative, pelanggan justru mempertimbangkan lebih jauh lagi ketika ingin membeli produk, (Sangadji dan Sopiah, 2013).

Menurut (Keller, 2013) pengukuran brand image yaitu subjektif artinya tidak ada ketentuan baku untuk mengukur brand image.

Brand image merupakan nama, istilah, simbol, ciri, metode atau kombinasi daripadanya untuk menandai produk/jasa dari pedagang atau kelompok pedagang serta untuk membedakannya dari para pesaing, (Ginting, 2011).
Kosmetik memang tidak jauh dari wanita, dan keanyakan memang memutuhkan riasan seperti alas bedak, bedak, lipstick,blus on, eye liner,mascara dan sebagainya. Saat ini dampak perkembangan kosmetik sangat menjamur oleh karena itu para industri kosmetik harus mampu mempertahankan citra yang baik di mata masyarakat.

Wardah adalah brand kosmetik lokal yang mengkat kosmetik Halal. Hal ini didukung dengan sertifikat halal yang dikeluarkan oleh MUI sejak tahun 1998 , wardah juga sudah mendapati lisensi dari BPOM yang diterbitkan oleh PT.Paragon Technologi and Innovation (Magdalena Dian, 2018). Wardah berkeyakinan bahwa Citra positif, dapat meningkatkan kepercayaan diri perempuan Indonesia untuk berkreasi. Dengan peralatan kosmetik yang benar, mereka dapat memperoleh yang baik. Wardah terbuat dari bahan menjamin keamanan dan kualitas tinggi dengan memproduksi beragai kosmetik semua jenis kulit.

La tulipe merupakan brand lokal yang didirikan pada tahun 1980, La tulipe merupakan elemen kosmetik efektif yang tidak mudah menimbulkan efek samping yang negative dan cocok untuk iklim tropis. Bahan bersahaja dan sudah diteliti secara ilmiah dan laboraturies serta dibawah control dokter dan para ahli farmasi. Ahli kecantikan dan dokter semakin banyak menggunakan produk La Tulipe di bidang kosmetik. Nama La Tulipe Cosmetiques sendiri diambil dari Perancis yang merupakan pusat mode dan kecantikan di dunia. Sejak tahun 2009, La Tulipe telah memperoleh sertifikat "halal" MUI, (Fimela, 2012).

Berdasarkan observasi dan wawancara langsung dari konsumen wardah dan La tulipe peneliti menemukan bahwa. Menurut sebagian pengguna wardah, Bedak padat wardah yang mudah pecah. Menurut pengguna kosmetik La Tulipe, variasi warna dari produk kosmetik La Tulipe ( foundation, bedak, BB cream) terlalu mencolok tidak sesuai 
dengan warna kulit. dan harga dari produk kosmetik La Tulipe lebih mahal ketimbang wardah. Namun demikian, konsumen dari kedua kosmetik tersebut enggan untuk mengganti kosmetiknya karna sudah nyaman dengan produk kosmetik pilihannya.

Pada pasar indusri kosmetik banyak yang beredar merek kosmetik lokal maupun nasional. Misalnya make over, maybelline, wardah, emina, La tulipe, dan sebagainya. Fokus penelitian ini pada merek kosmetik Wardah dan La tulipe, karena kosmetik merek ini telah dipercaya oleh sebagian besar masyarakat Indonesia di NTB khususnya di Kota Bima. Bahkan kosmetik tersebut banyak diminati dan sudah memiliki posisi yang kuat dibenak konsumen.

Berdasarkan penjelasan latar belakang diatas, maka peneliti ingin mengangkat dan mengetahui mengenai perbandingan citra merek dari kedua produk kosmetik tersebut dimata konsumen yang berjudul "Analisis Perbandingan Citra Merek Produk Kosmetik Wardah Dengan Kosmetik La Tulipe Di Kota Bima”.

\section{METODE}

Didalam penelitian ini metode yang digunakan yaitu penelitian komperatif merupakan penelitian yang sifatnya menguraikan tentang keadaan objek penelitian, khususnya pada citra merek produk kosmetik Wardah dan La tulipe. Populasi pada penelitian ini menunjuk pada masyarakat Kota Bima yaitu konsumen kosmetik merek Wardah dan La Tulipe yang jumlahnya tidak diketahui. Didalam penelitian ini sampel yang digunakan menurut (Taung \& Tielung, 2015) yaitu 50 responden pengguna kosmetik Wardah dan 50 pengguna kosmetik La tulipe, sehingga jumlah sampel secara keseluruhan sebanyak 100 responden. Instrumen yang diperlukan dalam penelitian ini adalah kuesioner atau angket yang akan diukur memakai skala likert bobotnya 1 sampai 5 . Teknik pengumpulan sampel didalam penelitian ini dikerjakan dengan teknik purposive sampling.

Teknik pengumpulan data yang digunakan antara lain observasi, wawancara, kuesioner, dan studi pustaka dengan menggunakan jenis data kuantitatif dan data primer. Penelitian ini dikerjakan di Kota Bima pada konsumen kosmetik Wardah dan La Tulipe. penelitian ini dilakukan pada bulan Januari sampai dengan bulan Februari 2021. Dengan menggunakan jenis data kuantitatif dari sumber data primer. Teknik analisis yang digunakan adalah uji validitas, uji reliabilitas, uji beda independen samples test dengan perangkat program SPSS version 26.

\section{HASIL DAN PEMBAHASAN Uji Validitas}

Uji validitas dikerjakan memakai rumus Pearson Correlation. Uji signifikansi dilakukan dengan menggunakan $r_{\text {tabel }}$ melalui uji dua sisi standar pada tingkat signifikan 0,05. Tes tersebut dapat dilihat pada tabel dibawah ini:

Table 1. Hasil Uji Validitas Citra Merek Produk Kosmetik Wardah

\begin{tabular}{ccccc}
\hline Item & $\begin{array}{c}\text { Sampel } \\
(\mathrm{N})\end{array}$ & $\mathrm{r}_{\text {hitung }}$ & $\mathrm{r}_{\text {tabel }}$ & Keterangan \\
\hline pernyataan 1 & 50 & 0.499 & 0.297 & Valid \\
pernyataan 2 & 50 & 0.411 & 0.297 & Valid \\
pernyataan 3 & 50 & 0.456 & 0.297 & Valid \\
pernyataan 4 & 50 & 0.594 & 0.297 & Valid
\end{tabular}




\begin{tabular}{ccccc} 
pernyataan 5 & 50 & 0.653 & 0.297 & Valid \\
pernyataan 6 & 50 & 0.658 & 0.297 & Valid \\
pernyataan 7 & 50 & 0.490 & 0.297 & Valid \\
pernyataan 8 & 50 & 0.735 & 0.297 & Valid \\
pernyataan 9 & 50 & 0.338 & 0.297 & Valid \\
pernyataan 10 & 50 & 0.432 & 0.297 & Valid \\
pernyataan 11 & 50 & 0.392 & 0.297 & Valid \\
pernyataan 12 & 50 & 0.519 & 0.297 & Valid \\
\hline
\end{tabular}

Sumber : Hasil Olahan data Primer SPSS 26, 2021

Dari tabel 1 diatas menunjukan bahwa hasil pengujian validitas terhadap Citra Merek Kosmetik Wardah dapat dikatakan semua item pernyataan untuk variabel terhadap Citra Merek Kosmetik
Wardah yang diajukan didalam penelitian ini, diakui efektif dan layak dipakai sebagai instrument penelitian karena berada di atas standar validitas ( $\left.\mathrm{r}_{\text {hitung }}\right)>$ $\left(\mathrm{r}_{\text {tabel }}\right)$ sebesar 0.279 .

Tabel 2. Hasil Uji Validitas Citra Merek Produk Kosmetik Wardah

\begin{tabular}{ccccc}
\hline Item & $\begin{array}{c}\text { Sampel } \\
(\mathrm{N})\end{array}$ & $\mathrm{r}_{\text {hitung }}$ & $\mathrm{r}_{\text {tabel }}$ & Keterangan \\
\hline pernyataan 1 & 50 & 0.546 & 0.297 & Valid \\
pernyataan 2 & 50 & 0.652 & 0.297 & Valid \\
pernyataan 3 & 50 & 0.468 & 0.297 & Valid \\
pernyataan 4 & 50 & 0.565 & 0.297 & Valid \\
pernyataan 5 & 50 & 0.530 & 0.297 & Valid \\
pernyataan 6 & 50 & 0.591 & 0.297 & Valid \\
pernyataan 7 & 50 & 0.456 & 0.297 & Valid \\
pernyataan 8 & 50 & 0.580 & 0.297 & Valid \\
pernyataan 9 & 50 & 0.504 & 0.297 & Valid \\
pernyataan 10 & 50 & 0.544 & 0.297 & Valid \\
pernyataan 11 & 50 & 0.564 & 0.297 & Valid \\
pernyataan 12 & 50 & 0.545 & 0.297 & Valid \\
\hline \multicolumn{5}{c}{ Sumber Hasil Olahan data Primer SPSS 26, 2021 }
\end{tabular}

Dari tabel 2 diatas menunjukan bahwa hasil pengujian validitas terhadap Citra Merek Kosmetik La Tulipe dapat dikatakan semua item pernyataan untuk variabel terhadap Citra Merek Kosmetik
La Tulipe yang diajukan didalam penelitian ini, diakui efektif dan layak dipakai sebagai instrument penelitian karena berada di atas standar validitas $\left(\mathrm{r}_{\text {hitung }}\right)>\left(\mathrm{r}_{\text {tabel }}\right)$ sebesar 0.279 . 


\section{Uji Reliabilitas}

Tabel 3. Hasil uji Reliabilitas

\begin{tabular}{cccc}
\hline Variabel & Cronbachs Alpha & Standar & Keterangan \\
\hline $\begin{array}{c}\text { Citra merek } \\
\text { kosmetik Wardah }\end{array}$ & 0,761 & 0,600 & Reliabel \\
\hline $\begin{array}{c}\text { Citra Merek } \\
\text { Kosmetik La } \\
\text { Tulipe }\end{array}$ & 0,791 & 0,600 & Reliabel \\
\hline
\end{tabular}

Sumber : Hasil Olahan data Primer SPSS 26, 2021

Dari tabel 3 di atas hasil uji Reliabilitas terhadap item pernyataan pada Citra Merek kosmetik Wardah dan Citra Merek kosmetik La Tulipe dengan nilai Apha yang didapat sudah lebih dari standar yang ditetapkan yaitu 0,6 artinya semua item pernyataan dari kuesioner dinyatakan akurat (reliabel) untuk digunakan dalam perhitungan penelitian.

\section{Uji Beda}

Uji Group Statistics

Tabel 4. Hasil Uji Group Statistics

\section{Group Statistics}

\begin{tabular}{|c|c|c|c|c|c|}
\hline & Kosmetik & Jumlah & Rata-rata & $\begin{array}{l}\text { Std. } \\
\text { Deviation }\end{array}$ & $\begin{array}{l}\text { Std.Error } \\
\text { Mean }\end{array}$ \\
\hline \multirow[t]{2}{*}{ citra merek } & kosmetik wardah & 50 & 51.0600 & 4.17676 & .59068 \\
\hline & $\begin{array}{l}\text { Kosmetik La } \\
\text { tulipe }\end{array}$ & 50 & 48.7600 & 4.65793 & .65873 \\
\hline
\end{tabular}

Sumber : Hasil Olahan data Primer SPSS 26, 2021

Berdasarkan tabel 4 group statistics diatas diketahui nilai rata-rata (Mean) citra merek kelompok kosmetik Wardah adalah sebesar 51,060, dan untuk kelompok kosmetik La Tulipe adalah 48,760. jadi kesimpulannya adalah nilai rata-rata citra merek kosmetik Wardah lebih baik ketimbang kosmetik La Tulipe.

\section{Uji Beda Independent Samples Test}

Dalam penelitian ini akan digunakan sampel independen, yaitu membandingkan rata-rata (mean) dari dua kelompok sampel yang berbeda yaitu sampel kosmetik merek Wardah dan kosmetik merek La tulipe. untuk melakukan uji beda t-test, peneliti mempertimbangkan apakah terdapat perbedaan yang signifikan antara kedua kelompok sampel berdasarkan kondisi sebagai berikut:

Jika $t_{\text {hitung }}>t_{\text {tabel }}$ dan probabilitas atau signifikansi ( $\mathrm{sig} 2$ tailed) > 0,05, maka $\mathrm{H}_{\mathrm{o}}$ diterima dan $\mathrm{H}_{\mathrm{a}}$ ditolak.

Jika $t_{\text {hitung }}<\mathrm{t}_{\text {tabel }}$ dan probabilitas atau signifikansi (sig 2 tailed) $<0,05$. Maka $\mathrm{H}_{\mathrm{o}}$ ditolak dan $\mathrm{H}_{\mathrm{a}}$ diterima. 
Tabel 5. Hasil Uji Beda Independen Samples test

Independen Samples Test

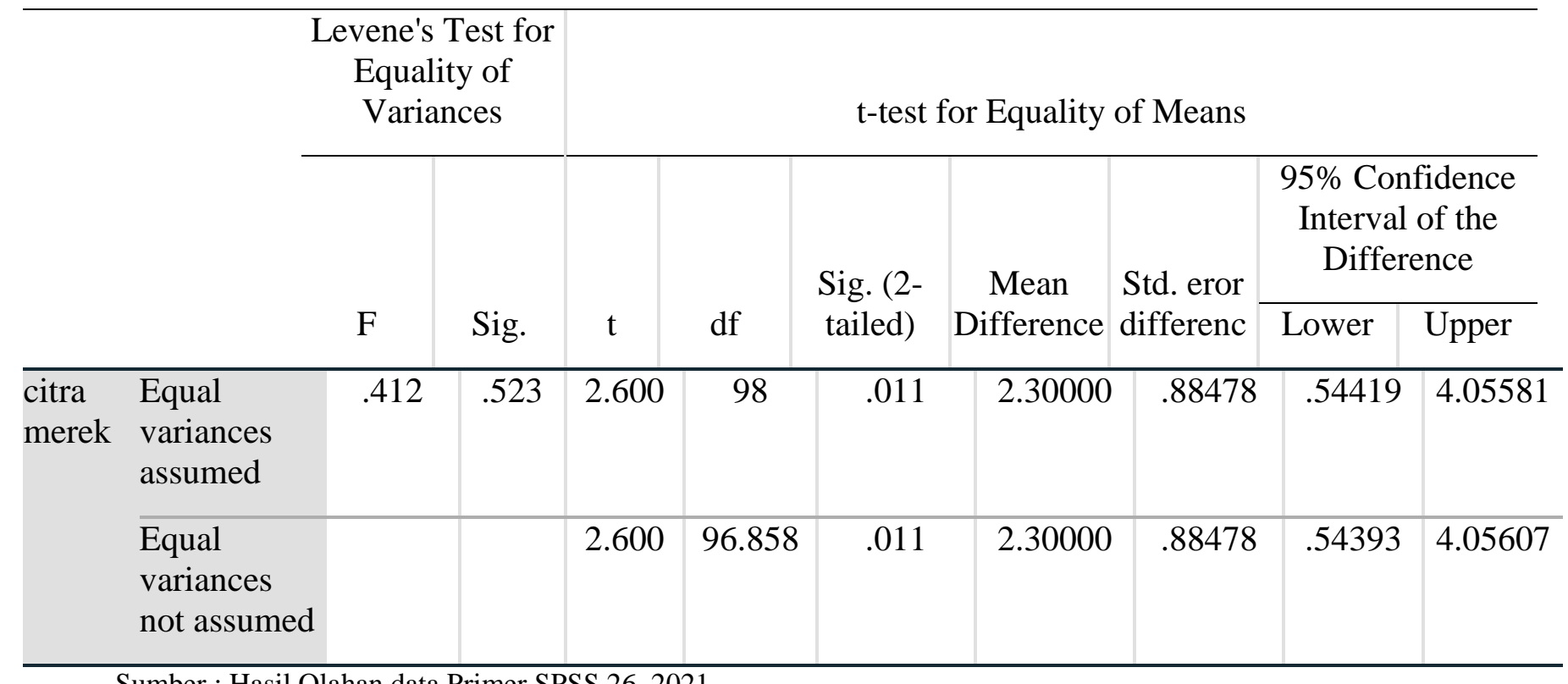

Sumber : Hasil Olahan data Primer SPSS 26, 2021

Berdasarkan uji beda Independent Sample Test dilihat bahwa nilai $t_{\text {hitung }}$ citra merek kosmetik Wardah dan La Tulipe sebesar 2,600 dengan Signifikansi 0,011. $\underline{\text { Jadi nilai }} \mathrm{t}_{\text {hitung }}>\mathrm{t}_{\text {tabel }}(2,600>1,984)$ dan nilai probabilitas atau sig.(2-tailed) 0,011 $<0,05$, maka $\mathrm{H}_{0}$ ditolak dan $\mathrm{H}_{\mathrm{a}}$ diterima yang berarti ada perbedaan yang signifikan citra merek kosmetik wardah dan La Tulipe.

Penelitian ini didukung oleh Pratama, (Pratama et al., 2018) Analisis perbandingan diferensiasi produk dan citra merek pada pembeli pakaian di Giordano

\section{KESIMPULAN DAN SARAN}

Kesimpulan

Berdasarkan hasil analisa statistik Independent Sampel Test, maka peneliti menarik kesimpulan bahwa ditemukan perbedaan yang signifikan Citra Merek Antara Produk kosmetik Wardah dan Produk kosmetik La Tulipe di Kota Bima.

\section{Saran}

1. Bagi perusahaan

Dari hasil penelitian tersebut terdapat perbedaan citra merek antara dan polo. (studi kasus di Manado Town Square), dimana variable citra merek pada pakaian Giordano dan Polo terdapat perbedaan yang signifikan Dan Penelitian ini juga didukung oleh penelitian (Taung \& Tielung, 2015) Analisis Perbandingan Diferensiasi Produk dan Citra Merek pada Motor Matic Honda Beat dan Yamaha Mio, dimana variable independen citra merek berpengaruh positif dan signifikan pada motor metic Honda beat dan Yamaha mio.

produk kosmetik wardah dengan kosmetik La Tulipe, maka disarankan untuk pihak Wardah dan La Tulipe harus mempertahankan Brand Image nya supaya tetap positif dimata pelanggan.

\section{Bagi peneliti selanjutnya}

Diharapkan bisa menjadi acuan untuk meneliti perbandingan citra merek kedua produk tersebut, dan dapat mengembangkan penelitian ini dengan variabel lain seperti kualitas produk, harga, diferensiasi produk dan kepercayaan merek serta metode penelitian dan 
memperluas sampel penelitian sebagai bahan perbandingan.

\section{DAFTAR PUSTAKA}

Erni Yunaida. (2017). Pengaruh Brand Image (Citra Merek) terhadap Loyalitas Konsumen Produk Oli Pelumas Evalube di Kota Langsa. Jurnal Manajemen Dan Keuangan, 6.

Fimela. (2012). La Tulip. Fimela.Com. https://www.fimela.com/lifestylerelationship/read/3715207/la-tulip

Ginting, H. N. F. (2011). Manajemen Pemasaran. CV Yrama Widya.

Keller, K. L. (2013). Strategic Brand Management: Building, Measuring, and Managing Brand Equity (4th ed). Person Education, Inc.

Magdalena Dian. (2018). 5 Brand Kosmetik Lokal yang Bisa jadi Pilihan Anda. BeautyJournal.Id. https://journal.sociolla.com/beauty/5brand-kosmetik-halal-lokal
Pratama, A., Sepang, J. L., \& Tawas, H. N. (2018). Analysis Comparative Of Product Differentation And Brand Image On Clothing Buyers In Giordano And Polo (Case Study In Manado Town Square 1). Analisis Perbandingan...... 3663 Jurnal EMBA, 6(4), 3663-3672.

Sangadji dan Sopiah. (2013). Perilaku Konsumen. Andi.

Taung, F. O., \& Tielung, M. (2015). Analisis Perbandingan Ddiferensiasi Produk Dan Citra Merek Pada Motor Matic Honda Beat Dan Yamaha Mio Di Kota Manado A Comperative Analysis Product Ddifferentation And Brand Image On Automatic Motor Honda Beat And Yamaha Mio In Manado City. In Analisis Perbandingan Diferensiasi« 226 Jurnal EMBA (Vol. 3). 